\title{
Efficacy and Safety of Combination Therapy Consisting of Angiotensin II Type 1 Receptor Blocker, Calcium Channel Blocker and Hydrochlorothiazide in Patients With Hypertension
}

\author{
Yuhei Shiga a, b, c, Shin-ichiro Miura ${ }^{\text {a, f }}$, Kota Motozato ${ }^{\text {a, d }}$, Yuka Yoshimine ${ }^{\text {a, b }}$, Kenji Norimatsu ${ }^{\text {a }}$, \\ Tadaaki Arimura ${ }^{a}$, Rie Koyoshi ${ }^{\mathrm{a}, ~ e}$, Joji Morii ${ }^{\mathrm{a}}$, Takashi Kuwano ${ }^{\mathrm{a}}$, Ken Inoue ${ }^{\mathrm{b}}$, \\ Tetsuro Shirotani ${ }^{\mathrm{c}}$, Kazuaki Fujisawa ${ }^{\mathrm{d}}$, Eiyu Matsunaga ${ }^{\mathrm{e}}, \mathrm{Keijiro} \mathrm{Saku}^{\mathrm{a}}$
}

\begin{abstract}
Background: Many patients continue to have high blood pressure (BP) even after treatment with high-dose (H)-angiotensin II type 1 receptor blocker (ARB)/calcium channel blocker $(\mathrm{CCB})$ or middledose (M)-ARB/CCB/hydrochlorothiazide (HCTZ).

Methods: Thirty-two hypertensive patients who had the use of H-ARB/ $\mathrm{CCB}$ or $\mathrm{M}-\mathrm{ARB} / \mathrm{CCB} / \mathrm{HCTZ}$ were enrolled in this study. We applied a changeover with a switch to H-ARB (telmisartan $80 \mathrm{mg} /$ day)/CCB (amlodipine $5 \mathrm{mg}$ /day or nifedipine CR $40 \mathrm{mg} /$ day)/HCTZ (12.5 mg/day).

Results: Systolic BP (SBP) and diastolic BP (DBP) were significantly decreased in all patients and in the $\mathrm{H}-\mathrm{ARB} / \mathrm{CCB}$ and $\mathrm{M}-\mathrm{ARB} / \mathrm{CCB} /$ HCTZ groups after 3 months. Percentage (\%) of patients who reached the target BP after 3 months (72\%) in all patients was significantly higher than that at 0 months $(19 \%)$. There were no serious adverse effects in any of the patients.
\end{abstract}

Conclusions: Combination therapy with $\mathrm{H}-\mathrm{ARB} / \mathrm{CCB} / \mathrm{HCTZ}$ was associated with a significant reduction of BP.

Keywords: Blood pressure; Calcium channel blocker; Angiotensin II type 1 receptor blocker; Hydrochlorothiazide

\section{Introduction}

Most patients with hypertension (HTN) require two or more

Manuscript accepted for publication December 20, 2016

aDepartment of Cardiology, Fukuoka University School of Medicine, Fukuoka, Japan

bInoue Hospital, Fukuoka, Japan

'Shirotani Hospital, Fukuoka, Japan

dFujisawa Clinic, Fukuoka, Japan

eMatsunaga Hospital, Fukuoka, Japan

${ }^{f}$ Corresponding Author: Shin-ichiro Miura, Department of Cardiology, Fukuoka University School of Medicine, 7-45-1 Nanakuma, Jonan-ku, Fukuoka 814-0180, Japan. Email: miuras@cis.fukuoka-u.ac.jp

doi: https://doi.org/10.14740/jocmr2838w drugs to achieve their target blood pressure (BP) [1]. In fact, large-scale clinical trials have shown that thiazide diuretics and/or calcium channel blockers (CCBs) are frequently needed in addition to angiotensin II type 1 receptor blockers (ARBs) to achieve adequate BP control [2]. Although various guidelines recommend the use of combinations of ARBs and CCBs or diuretics [3, 4], we use three kinds of anti-hypertensive drugs when two drugs do not provide a significant reduction of BP. Although approximately $15 \%$ of patients receive three drugs, there have been few reports on whether combination therapy with three drugs is superior to a combination of two drugs [5]. Many patients continue to show a high BP even after treatment with high-dose (H) ARB/CCB or middle-dose (M)-ARB/ $\mathrm{CCB} /$ hydrochlorothiazide (HCTZ), although optimal BP control is associated with remarkable clinical benefits with regard to cardiovascular and renal protection. Therefore, we analyzed whether a changeover with a switch from combination therapy with $\mathrm{H}-\mathrm{ARB} / \mathrm{CCB}$ or $\mathrm{M}-\mathrm{ARB} / \mathrm{CCB} / \mathrm{HCTZ}$ to combination therapy with $\mathrm{H}-\mathrm{ARB} / \mathrm{CCB} / \mathrm{HTCZ}$ can offer better efficacy and safety in patients with HTN.

\section{Methods}

\section{Study design}

Thirty-two hypertensive patients who had the use of H-ARB (telmisartan $80 \mathrm{mg} /$ day)/CCB (amlodipine $5 \mathrm{mg}$ /day or nifedipine CR $40 \mathrm{mg} /$ day) or M-ARB (losartan $50 \mathrm{mg} /$ day)/CCB (amlodipine $5 \mathrm{mg} /$ day or nifedipine CR $40 \mathrm{mg} /$ day)/HCTZ $(12.5 \mathrm{mg} /$ day) more than 1 month (average $3.9 \pm 6.9$ months) were enrolled. We applied a changeover with a switch from $\mathrm{H}-\mathrm{ARB} / \mathrm{CCB}$ (H-ARB/CCB group) or M-ARB/CCB/HCTZ (M-ARB/CCB/HCTZ group) to H-ARB (telmisartan $80 \mathrm{mg} /$ day)/CCB (amlodipine $5 \mathrm{mg} /$ day or nifedipine CR $40 \mathrm{mg}$ / day)/HCTZ (12.5 mg/day). We did not change the kind or dose of CCB and analyzed various parameters at baseline $(0$ months) and after 3 months. We excluded patients with secondary HTN, heart failure of NYHA grade III or IV, liver dysfunction, renal dysfunction (defined as a serum creatinine $(\mathrm{Cr})$ level of more than $2.0 \mathrm{mg} / \mathrm{dL}$ ), pregnancy, or a history of allergy to ARB, CCB or HCTZ. The target BP followed the Japanese Society of Hypertension Guidelines for the Manage- 
Table 1. Baseline Patient Characteristics in All Patients and in the H-ARB/CCB and M-ARB/CCB/HTCZ Groups

\begin{tabular}{|c|c|c|c|}
\hline & All patients $(n=32)$ & H-ARB/CCB $(n=20)$ & M-ARB/CCB/HTCZ $(n=12)$ \\
\hline Age, years & $69 \pm 15$ & $69 \pm 16$ & $68 \pm 13$ \\
\hline Gender (male), n (\%) & $16(50)$ & $11(55)$ & $5(42)$ \\
\hline Smoking, n (\%) & $11(34)$ & $8(40)$ & $3(25)$ \\
\hline BMI, $\mathrm{kg} / \mathrm{m}^{2}$ & $23.9 \pm 4.3$ & $23.8 \pm 4.6$ & $24.0 \pm 3.9$ \\
\hline $\mathrm{WC}, \mathrm{cm}$ & $85.7 \pm 10.2$ & $86.1 \pm 11.1$ & $87.0 \pm 8.9$ \\
\hline $\mathrm{DL}, \mathrm{n}(\%)$ & $18(56)$ & $10(50)$ & $8(67)$ \\
\hline $\mathrm{LDL}-\mathrm{C}, \mathrm{mg} / \mathrm{dL}$ & $104 \pm 32$ & $106 \pm 35$ & $100 \pm 27$ \\
\hline $\mathrm{HDL}-\mathrm{C}, \mathrm{mg} / \mathrm{dL}$ & $52 \pm 12$ & $51 \pm 13$ & $52 \pm 10$ \\
\hline $\mathrm{TG}, \mathrm{mg} / \mathrm{dL}$ & $145 \pm 92$ & $138 \pm 92$ & $155 \pm 95$ \\
\hline DM, n (\%) & $5(16)$ & $3(15)$ & $2(17)$ \\
\hline Fasting glucose, $\mathrm{mg} / \mathrm{dL}$ & $102 \pm 29$ & $102 \pm 35$ & $103 \pm 16$ \\
\hline HbAlc, $\%$ & $5.3 \pm 0.9$ & $5.4 \pm 1.0$ & $5.2 \pm 0.5$ \\
\hline HU, n (\%) & $6(19)$ & $4(20)$ & $2(12)$ \\
\hline $\mathrm{UA}, \mathrm{mg} / \mathrm{dL}$ & $5.4 \pm 1.3$ & $5.3 \pm 1.2$ & $5.7 \pm 1.4$ \\
\hline CAD, n (\%) & $4(13)$ & $4(20)$ & $0(0)$ \\
\hline
\end{tabular}

Continuous variables are expressed as mean \pm SD. BMI: body mass index; WC: waist circumference; DL: dyslipidemia; LDL-C: low-density lipoprotein cholesterol; HDL-C: high-density lipoprotein cholesterol; TG: triglyceride; DM: diabetes mellitus; HbA1c: hemoglobin A1c; HU: hyperuricemia; UA: uric acid; CAD: coronary artery disease.

ment of Hypertension 2009 (JSH2009) [3]. The protocol in this study was approved by the ethics committee of Fukuoka University Hospital, and all subjects gave their informed consent to participate.

\section{Evaluation of clinical parameters}

Office systolic BP (SBP), diastolic BP (DBP) and pulse rate (PR) measurements were obtained at $0,1,2$ and 3 months. Body weight (BW), blood and urinary levels of biochemical parameters were obtained at 0 and 3 months. BP was determined as the mean of two measurements obtained in an office setting by the conventional cuff method using a mercury sphygmomanometer after at least 5 min of rest. All of the blood samples were collected in the morning after the patients had fasted overnight. Data regarding serum levels of biochemical parameters, such as high-density lipoprotein-cholesterol (HDL-C), low-density lipoprotein-cholesterol (LDL-C), triglycerides (TG), uric acid (UA), creatinine (Cr), fasting plasma glucose (FPG), hemoglobin A1c (HbA1c), sodium (Na) and potassium $(\mathrm{K})$ were collected in all patients. Body mass index (BMI) was

Table 2. Medications in All Patients and in the $H-A R B / C C B$ and $M-A R B / C C B / H T C Z$ Groups

\begin{tabular}{|c|c|c|c|}
\hline & All patients $(n=32)$ & H-ARB/CCB $(n=20)$ & M-ARB/CCB/HTCZ $(n=12)$ \\
\hline \multicolumn{4}{|l|}{ Medication use } \\
\hline \multicolumn{4}{|l|}{$\mathrm{CCBs}$} \\
\hline Amlodipine 5 mg, n (\%) & $7(22)$ & $6(30)$ & $1(8)$ \\
\hline$\beta$-blocker, n (\%) & $1(3)$ & $1(5)$ & $0(0)$ \\
\hline \multicolumn{4}{|l|}{ Medication use before changeover } \\
\hline ARBs, n (\%) & $20(63)$ & $20(100)$ & $0(0)$ \\
\hline Telmisartan 80 mg, n (\%) & $12(38)$ & $12(60)$ & $0(0)$ \\
\hline Olmesartan 40 mg, n (\%) & $6(19)$ & $6(30)$ & $0(0)$ \\
\hline Valsartan 160 mg, n (\%) & $2(6)$ & $2(10)$ & $0(0)$ \\
\hline
\end{tabular}

CCBs: calcium channel blockers; ARBs: angiotensin II receptor blockers; HCTZ: hydrochlorothiazide. 


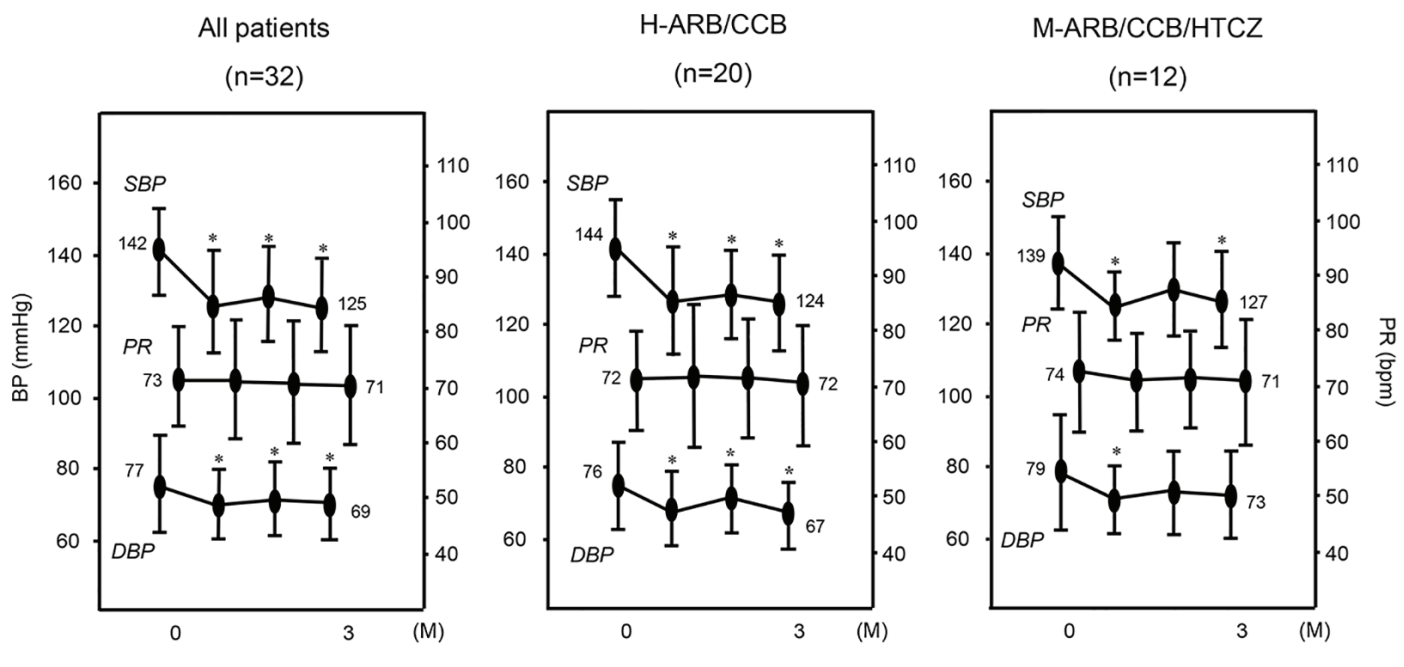

Figure 1. Changes in SBP, DBP and PR in all patients $(n=32)$ and in the H-ARB/CCB $(n=20)$ and M-ARB/CCB/HCTZ $(n=12)$ groups. ${ }^{*} P<0.05$ vs. 0 months $(M)$.

calculated as BW $(\mathrm{kg}) /$ height $(\mathrm{m})^{2}$.

The characteristics of the patients with regard to history of dyslipidemia (DL), diabetes mellitus (DM), hyperuricemia (HU), smoking status and medication use were obtained from medical records. Patients with LDL-C $\geq 140 \mathrm{mg} / \mathrm{dL}, \mathrm{TG} \geq$ $150 \mathrm{mg} / \mathrm{dL}$, and/or HDL-C $<40 \mathrm{mg} / \mathrm{dL}$, or who were receiving lipid-lowering therapy, were considered to have DL. DM was defined using the Japanese Diabetes Association criteria or the use of a glucose-lowering drug. HU was defined as a serum UA level of $\geq 7.0 \mathrm{mg} / \mathrm{dL}$ or the use of uric acid-lowering drugs.

\section{Statistical analysis}

Statistical analysis was performed using the Stat View statistical software package (Stat View 5; SAS Institute Inc., Cary, NC, USA) at Fukuoka University (Fukuoka, Japan). Data are presented as the mean \pm standard deviation (SD). Categorical and continuous variables were compared between the groups by a Chi-square analysis and unpaired $t$-test, respectively. Changes in SBP, DBP, PR, and clinical parameters following therapy were analyzed by the paired $t$-test. A value of $\mathrm{P}<0.05$ was considered significant.

\section{Results}

\section{Patient characteristics in all patients and in the $\mathrm{H}-\mathrm{ARB} /$ $\mathrm{CCB}$ and $\mathrm{M}-\mathrm{ARB} / \mathrm{CCB} / \mathrm{HTCZ}$ groups}

Table 1 shows the characteristics of the 32 patients, who consisted of $16(50 \%)$ males. The prevalence of DL, DM and HU was 56\%, 16\% and 19\%, respectively. There were no significant differences in these patient characteristics between the H-ARB/CCB and M-ARB/M-CCB/HTCZ groups. The percentage use of $\beta$-blocker and $\alpha$-blocker was $3 \%$ and $3 \%$, respectively (Table 2). There were no significant differences in medications between the groups. We did not change these medications throughout the study period.

Time courses of $B P$ and $P R$ in all patients and in the $H$ $\mathrm{ARB} / \mathrm{CCB}$ and $\mathrm{M}-\mathrm{ARB} / \mathrm{CCB} / \mathrm{HTCZ}$ groups

The time courses of BP and PR are shown in Figure 1. In all patients, significant reductions in SBP $(142 \pm 12$ to $125 \pm 15$ $\mathrm{mm} \mathrm{Hg})$ and DBP $(77 \pm 13$ to $69 \pm 11 \mathrm{~mm} \mathrm{Hg})$, but not PR, were observed after 3 months. In the H-ARB/CCB group, SBP and DBP after 3 months were significantly lower than those at 0 months (SBP: $144 \pm 12$ to $124 \pm 15 \mathrm{~mm} \mathrm{Hg}$, DBP: $76 \pm 10$ to $67 \pm 10 \mathrm{~mm} \mathrm{Hg}$ ). In the M-ARB/CCB/HTCZ group, SBP after 3 months was significantly lower than that at 0 months (SBP: $139 \pm 12$ to $127 \pm 15 \mathrm{~mm} \mathrm{Hg}$ ).

Percentages (\%) of patients who reached the target $B P$ at 0 and 3 months in all patients and in the $H-A R B / C C B$ and M-ARB/CCB/HTCZ groups

The $\%$ patients who reached the target BP at 3 months in all patients $(72 \%)$ and in $\mathrm{H}-\mathrm{ARB} / \mathrm{CCB}$ group $(80 \%)$ was significantly higher than that at 0 months (all patients (19\%) and $\mathrm{H}-$ ARB/CCB group (15\%) (Fig. 2). In addition, \% patients who reached the target $\mathrm{BP}$ at 3 months $(58 \%)$ tended to be higher than that at 0 months $(25 \%)$ in the $\mathrm{M}-\mathrm{ARB} / \mathrm{CCB}(\mathrm{P}<0.10)$.

\section{$\triangle \mathrm{SBP}$ and $\triangle \mathrm{DBP}$ in all patients and in the $\mathrm{H}-\mathrm{ARB} / \mathrm{CCB}$ and $\mathrm{M-ARB/CCB/HTCZ}$ groups}

Changes in SBP and DBP from 0 to 3 months $(\Delta=$ the value at 3 months minus the value at 0 months) are shown in Figure 3. There were no significant differences in $\triangle \mathrm{SBP}$ or $\triangle \mathrm{DBP}$ 


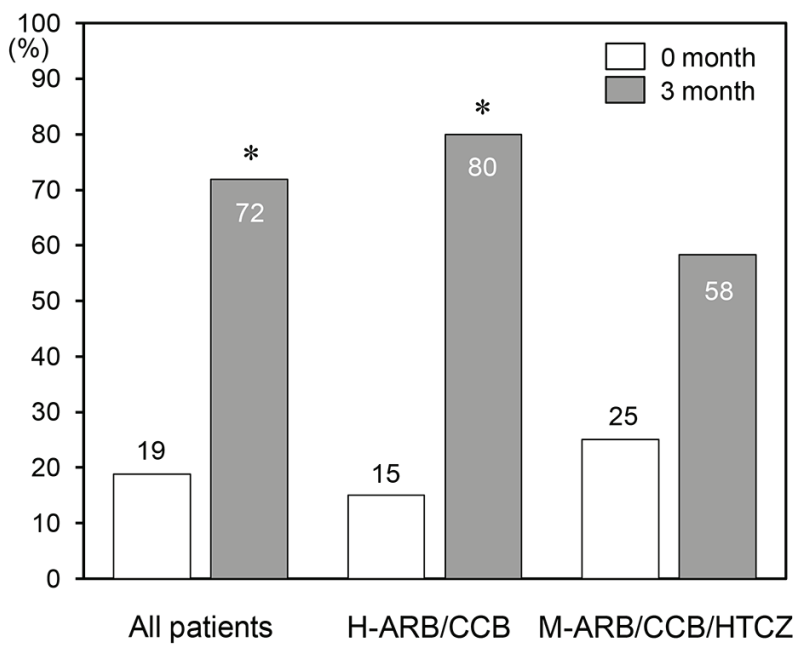

Figure 2. Percentages (\%) of patients who reached the target $\mathrm{BP}$ at 0 and 3 months in all patients and in the H-ARB/CCB and M-ARB/CCB/ HTCZ groups. *P $<0.05$ vs. 0 months.

among all patients or the $\mathrm{H}-\mathrm{ARB} / \mathrm{CCB}$ and $\mathrm{M}-\mathrm{ARB} / \mathrm{CCB} /$ HTCZ groups.

\section{Changes in biochemical parameters in all patients and in the $\mathrm{H}-\mathrm{ARB} / \mathrm{CCB}$ and $\mathrm{M}-\mathrm{ARB} / \mathrm{CCB} / \mathrm{HTCZ}$ groups}

As shown in Table 3, there were no significant changes in biochemical parameters including $\mathrm{Cr}$, BNP and the lipid profile in all patients or the $\mathrm{H}-\mathrm{ARB} / \mathrm{CCB}$ and $\mathrm{M}-\mathrm{ARB} / \mathrm{CCB} / \mathrm{HTCZ}$ groups. On the other hand, all patients and the $\mathrm{H}-\mathrm{ARB} / \mathrm{CCB}$ group showed significantly increased serum UA, and all patients showed significantly increased serum $\mathrm{HbAlc}$.

\section{Discussion}

In the present study, combination therapy with $\mathrm{H}-\mathrm{ARB} / \mathrm{CCB} /$ HTCZ induced a significant reduction of BP after patients switched from $\mathrm{H}-\mathrm{ARB} / \mathrm{CCB}$ or $\mathrm{M}-\mathrm{ARB} / \mathrm{CCB} / \mathrm{HTCZ}$. BP control is the best strategy for achieving remarkable clinical benefits with regard to cardiovascular and renal protection. There are two main explanations for why H-ARB/CCB/HTCZ induced a significant reduction in BP. First, $12.5 \mathrm{mg} /$ day of HCTZ significantly increased plasma renin activity (PRA) [6]. In this study, the blockade of PRA activation by HTCZ using H-ARB (telmisartan $80 \mathrm{mg} /$ day) may be stronger than that using M-ARB (losartan $50 \mathrm{mg}$ /day). Second, telmisartan 80 $\mathrm{mg}$ /day itself had significantly greater depressor effects than losartan $50 \mathrm{mg} /$ day [7].

In this study, combination therapy with $\mathrm{H}-\mathrm{ARB} / \mathrm{CCB} /$ HTCZ significantly increased serum UA after patients were switched from H-ARB/CCB because of the addition of HTCZ. Telmisartan in Micombi ${ }^{\circledR}$ BP partially activates peroxisome proliferator-activated receptor- $\gamma$ [8], which may improve insulin sensitivity. This effect may be useful in hypertensive patients with insulin resistance or DM [9]. Unexpectedly, although $\mathrm{H}-\mathrm{ARB}$ (telmisartan $80 \mathrm{mg} /$ day) $/ \mathrm{CCB} / \mathrm{HTCZ}$ significantly increased serum $\mathrm{HbAlc}$ levels in all patients, there were no serious adverse effects in any of the patients.
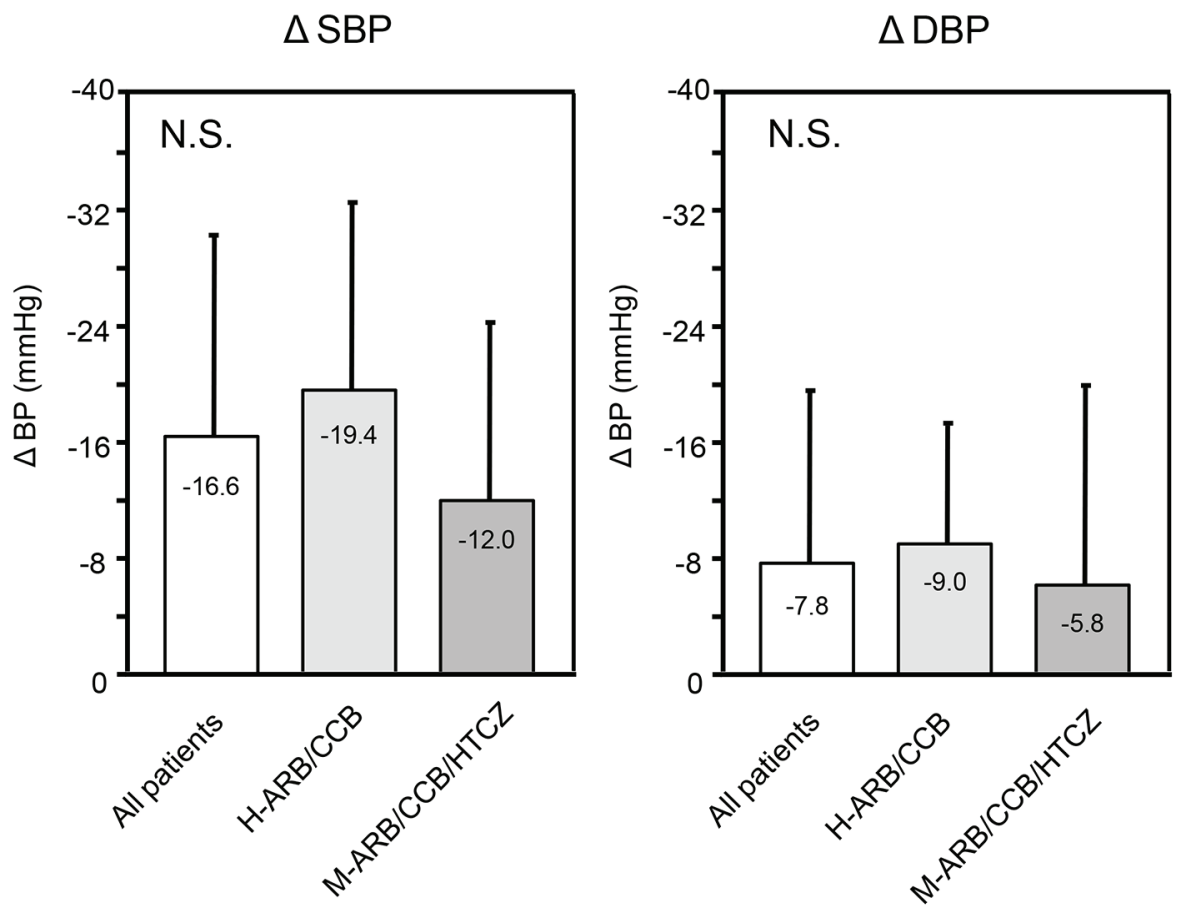

Figure 3. $\triangle$ SBP and $\triangle \mathrm{DBP}$ in all patients $(n=32)$ and in the H-ARB/CCB $(n=20)$ and M-ARB/CCB/HCTZ $(n=12)$ groups over 3 months. $\triangle$ indicates the value at 3 months minus the value at 0 months. NS: not significant. 
Table 3. Biochemical Parameters at 0 and 3 Months in All Patients and in the $H-A R B / C C B$ and M-ARB/CCB/HTCZ Groups

\begin{tabular}{|c|c|c|c|c|c|c|}
\hline & \multicolumn{2}{|c|}{ All patients $(n=32)$} & \multicolumn{2}{|c|}{ H-ARB/CCB $(n=20)$} & \multicolumn{2}{|c|}{$\mathrm{M}-\mathrm{ARB} / \mathrm{CCB} / \mathrm{HTCZ}(\mathrm{n}=12)$} \\
\hline & 0 months & 3 months & 0 months & 3 months & 0 months & 3 months \\
\hline $\mathrm{BUN}, \mathrm{mg} / \mathrm{dL}$ & $18 \pm 11$ & $20 \pm 12$ & $17 \pm 12$ & $21 \pm 15$ & $20 \pm 7$ & $19 \pm 6$ \\
\hline $\mathrm{Cr}, \mathrm{mg} / \mathrm{dL}$ & $0.9 \pm 0.4$ & $1.0 \pm 0.4$ & $0.9 \pm 0.5$ & $1.0 \pm 0.4$ & $1.0 \pm 0.4$ & $0.9 \pm 0.4$ \\
\hline $\mathrm{eGFR}, \mathrm{mL} / \mathrm{min} / 1.73 \mathrm{~m}^{2}$ & $63 \pm 21$ & $61 \pm 23$ & $67 \pm 22$ & $63 \pm 25$ & $56 \pm 18$ & $60 \pm 20$ \\
\hline $\mathrm{UA}, \mathrm{mg} / \mathrm{dL}$ & $5.4 \pm 1.3$ & $6.0 \pm 1.3^{*}$ & $5.3 \pm 1.2$ & $6.0 \pm 1.3^{*}$ & $5.7 \pm 1.4$ & $6.2 \pm 1.3$ \\
\hline $\mathrm{Na}, \mathrm{mEq} / \mathrm{L}$ & $141 \pm 2$ & $140 \pm 3$ & $141 \pm 2$ & $140 \pm 3$ & $140 \pm 2$ & $140 \pm 3$ \\
\hline $\mathrm{K}, \mathrm{mEq} / \mathrm{L}$ & $4.0 \pm 0.5$ & $4.1 \pm 0.7$ & $4.0 \pm 0.6$ & $4.2 \pm 0.7$ & $4.0 \pm 0.4$ & $4.1 \pm 0.6$ \\
\hline $\mathrm{TG}, \mathrm{mg} / \mathrm{dL}$ & $145 \pm 92$ & $135 \pm 72$ & $138 \pm 92$ & $120 \pm 61$ & $155 \pm 95$ & $159 \pm 84$ \\
\hline LDL-C, mg/dL & $104 \pm 32$ & $102 \pm 30$ & $106 \pm 35$ & $104 \pm 34$ & $127 \pm 46$ & $129 \pm 31$ \\
\hline $\mathrm{HDL}-\mathrm{C}, \mathrm{mg} / \mathrm{dL}$ & $52 \pm 12$ & $56 \pm 16$ & $51 \pm 13$ & $58 \pm 18$ & $52 \pm 10$ & $52 \pm 10$ \\
\hline $\mathrm{FPG}, \mathrm{mg} / \mathrm{dL}$ & $102 \pm 229$ & $116 \pm 81$ & $102 \pm 35$ & $122 \pm 10$ & $103 \pm 16$ & $106 \pm 24$ \\
\hline HbA1c, $\%$ & $5.3 \pm 0.9$ & $5.5 \pm 0.8^{*}$ & $5.4 \pm 1.0$ & $5.5 \pm 1.0$ & $5.2 \pm 0.5$ & $5.4 \pm 0.5$ \\
\hline BNP, pg/mL & $67 \pm 92$ & $55 \pm 72$ & $66 \pm 70$ & $66 \pm 87$ & $70 \pm 124$ & $36 \pm 28$ \\
\hline
\end{tabular}

BUN: blood urea nitrogen; Cr: creatinine; eGFR: estimated glomerular filtration rate; UA: uric acid; Na: sodium; K: potassium; TG: triglyceride; LDL-C: low-density lipoprotein cholesterol; HDL-C: high-density lipoprotein cholesterol; FPG: fast plasma glucose; HbA1c: hemoglobin A1c; BNP: brain natriuretic peptide. ${ }^{*} \mathrm{P}<0.05$ vs. 0 months.

\section{Study limitations}

This study has three important limitations. First, the sample size was relatively small, which limits our ability to determine significance. Second, we applied a changeover with switching from $\mathrm{H}-\mathrm{ARB} / \mathrm{CCB}$ or $\mathrm{M}-\mathrm{ARB} / \mathrm{CCB} / \mathrm{HCTZ}$. A crossover study would have been preferable. Third, we measured BP and PR for only 3 months and did not evaluate the clinical outcome. Long-term prospective studies are needed to clarify the limitation.

\section{Conclusions}

Combination therapy with $\mathrm{H}-\mathrm{ARB} / \mathrm{CCB} / \mathrm{HCTZ}$ was associated with a significant reduction of BP. Although serum UA and $\mathrm{HbA} 1 \mathrm{c}$ increased after 3 months, there were no serious adverse effects in any of the patients.

\section{Conflicts of Interest}

KS is a Chief Director and SM is a Director of NPO Clinical and Applied Science, Fukuoka, Japan. KS has an Endowed "Department of Molecular Cardiovascular Therapeutics" supported by MSD, Co. Ltd. SM belongs to the Department of Molecular Cardiovascular Therapeutics, which is supported by MSD, Co. Ltd.

\section{References}

1. Dahlof B, Sever PS, Poulter NR, Wedel H, Beevers DG, Caulfield M, Collins R, et al. Prevention of cardiovascular events with an antihypertensive regimen of amlodipine adding perindopril as required versus atenolol adding bendroflumethiazide as required, in the Anglo-Scandinavian Cardiac Outcomes Trial-Blood Pressure Lowering Arm (ASCOT-BPLA): a multicentre randomised controlled trial. Lancet. 2005;366(9489):895-906.

2. Kato J, Eto T. Diuretics in the LIFE study. Lancet. 2004;364(9432):413; author reply 413-414.

3. Ogihara T, Kikuchi K, Matsuoka H, Fujita T, Higaki J, Horiuchi M, Imai Y, et al. The Japanese Society of Hypertension Guidelines for the Management of Hypertension (JSH 2009). Hypertens Res. 2009;32(1):3-107.

4. Mancia G, De Backer G, Dominiczak A, Cifkova R, Fagard R, Germano G, Grassi G, et al. 2007 Guidelines for the Management of Arterial Hypertension: The Task Force for the Management of Arterial Hypertension of the European Society of Hypertension (ESH) and of the European Society of Cardiology (ESC). J Hypertens. 2007;25(6):1105-1187.

5. Sato A, Watanabe S, Okubo S, Toi T, Doi T, Nakano H, Tada J, et al. The therapeutic importance of home blood pressure assessment and combination antihypertensive therapy for achieving target blood pressure control: Ibaraki hypertension assessment trial. Hypertens Res. 2010;33(12):1264-1271.

6. Villamil A, Chrysant SG, Calhoun D, Schober B, Hsu H, Matrisciano-Dimichino L, Zhang J. Renin inhibition with aliskiren provides additive antihypertensive efficacy when used in combination with hydrochlorothiazide. J Hypertens. 2007;25(1):217-226.

7. Bakris G, Burgess E, Weir M, Davidai G, Koval S. Telmisartan is more effective than losartan in reducing proteinuria in patients with diabetic nephropathy. Kidney Int. 2008;74(3):364-369.

8. Benson SC, Pershadsingh HA, Ho CI, Chittiboyina A, 
Desai P, Pravenec M, Qi N, et al. Identification of telmisartan as a unique angiotensin II receptor antagonist with selective PPARgamma-modulating activity. Hypertension. 2004;43(5):993-1002.
9. Suksomboon N, Poolsup N, Prasit T. Systematic review of the effect of telmisartan on insulin sensitivity in hypertensive patients with insulin resistance or diabetes. J Clin Pharm Ther. 2012;37(3):319-327. 